\title{
The effect of ethical leadership on subjective wellbeing, given the moderator job satisfaction (a case study of private hospitals in Mashhad)
}

\author{
Azar Kaffashpoor ${ }^{1 *}$ (D) and Samaneh Sadeghian ${ }^{2}$
}

\begin{abstract}
Background: The emerging ethical leadership, a unique approach in leadership viewpoint, has provided the ground for constructing and advancing individual and managerial efficiency by highlighting ethics in organizations. The present study aims to investigate the influence of Ethical Leadership on Subjective Wellbeing, Given the Moderator Job Satisfaction in Private Hospitals in Mashhad.

Methods: This descriptive-correlational research design stud was conducted in 2015-2016 to inspect the possible effect of ethical leadership on subjective wellbeing and job satisfaction, as dependent and mediator variables, among the Iranian private hospitals' nurses in Mashhad. Simple random sampling method was used to select the sample of 166 nurses out of the population of 730 nurses, in total. The valid and reliable adapted version of the questionnaire designed by Yang (2014) was used to collect the data, and structural equation modeling (SEM) was used to analyze the data set.

Results: The results showed that there is a positive significant correlation between ethical leadership and job satisfaction. More specifically, the findings indicated that Ethical leadership affected the subjective wellbeing of nurses through job satisfaction both directly and indirectly.

Conclusions: The findings illustrated that focus on ethics and ethically-oriented leaders in hospitals, enriched by job satisfaction can lead to the nurses' subjective wellbeing by providing them a positive climate.
\end{abstract}

Keywords: Ethical leadership, Job satisfaction, Organizational performance, Subjective wellbeing (SWB)

\section{Background}

The issue of organizational health, fulfilled through the law or ethics, is a vital consideration in any organization to survive and long-term success. Thus, ethics and morality must be taken into account as key sources of ethical guidelines for the leaders and personnel in organizations. Besides, very recently, advancing in issues such as

\footnotetext{
* Correspondence: kafashpor@um.ac.ir

${ }^{1}$ Management Department, Faculty of Economics and Administrative Sciences, Ferdowsi University of Mashhad, Mashhad, Iran

Full list of author information is available at the end of the article
}

Altruism, honesty, empowerment, fairness and justice (e.g., $[1,2])$ has been of much interest to the researchers because of current scandals, which accordingly led to the investigation of ethical leadership concept in the early twentieth century [3].

Consistent with the social learning theory, personnel acquire the way of communicating with others through imitating and monitoring organizations' leaders' [4]. However, the number of studies concentrating on the practical application of this theory, specifically about ethical leadership, is so scarce [5]. From a social learning

(C) The Author(s). 2020 Open Access This article is licensed under a Creative Commons Attribution 4.0 International License, which permits use, sharing, adaptation, distribution and reproduction in any medium or format, as long as you give appropriate credit to the original author(s) and the source, provide a link to the Creative Commons licence, and indicate if changes were made. The images or other third party material in this article are included in the article's Creative Commons licence, unless indicated otherwise in a credit line to the material. If material is not included in the article's Creative Commons licence and your intended use is not permitted by statutory regulation or exceeds the permitted use, you will need to obtain permission directly from the copyright holder. To view a copy of this licence, visit http://creativecommons.org/licenses/by/4.0/. The Creative Commons Public Domain Dedication waiver (http://creativecommons.org/publicdomain/zero/1.0/) applies to the data made available in this article, unless otherwise stated in a credit line to the data. 
viewpoint, ethical leaders are considered as role models forming suitable manners and standards in an organization [6]. Thus, ethical leadership is defined as the confirmation and advancement of normatively suitable personal and interpersonal behavior in two-way communications, reinforcement and decision-making [6-9]. This leadership model can be perceived in more tangible terms by a triple behavioral dimension: (1) leader's 'fairness' which refers to being fair, trustworthy and honest meaning that ethical leaders treat others with respect, do not differentiate among others and make fair decisions. (2) leader's 'power sharing' behavior which refers to giving juniors a voice, listen to their input, and allow them to take part in decision-making. (3) leader's 'role clarification' referring to working clearly, clarifying expectations, and communicating openly in order to let the followers understand what is expected from them [10]. According to the theory of social learning, followers have a tendency to pay attention and follow their ethical leaders' outlooks, values, and manners because leaders' attraction and trustworthiness as role models and source of guidance draw attention to their modeled behavior [6]. Some probable positive effects of ethical leadership are job satisfaction (e.g., [11-14]), and employee wellbeing (e.g., $[14,15])$.

Subjective wellbeing, in working and managerial settings, refers to the employee's insight and assessment of the quality of (working) life, social and psychological working in those settings [16]. Previous studies confirmed the relation between leader's manners and employee's wellbeing (e.g., [17], (https://doi.org/10.1097/ JOM.0b013e31817e918d)]), and the effect of leadership styles such as transformational, honorable and ethical leadership on the employee's subjective wellbeing (e.g., $[15,18,19])$. As the Conservation of Resources (COR) theory proposes, people struggle to remember, protect, and construct resources with the fear of the potential or actual loss of these valued resources. Resources, then, are the single essential unit for understanding stress. COR theory asserts that resources, such as ethical leadership, aid employees to gain more resources. This starts a positive spiral of resources, which can positively impact on wellbeing. Ethical leaders can offer job resources by effectively protecting employees, defending them from injustice or mobilizing job resources, which positively affect employee's wellbeing [20]. Ethical leaders are caring, honest and reliable. They encourage employees to state their worries and make fair decisions on importance issues [21]. In doing so, ethical leaders are impartial and truthful and provide personnel with a safety environment to fall back on while experiencing low levels of wellbeing at work settings. Accordingly, personnel receive help, attention, and emotional care from their leader. Accordingly, Zou et al., [22] show the effect of spiritual leadership on the Chinese nurses' subjective well-being [23]. Teimouri et al., [24] also confirmed the effect of ethical leadership on psychological wellbeing of employees [25]. Sarwar et al., [26] also show the direct positive relation between ethical leadership and employee well-being [22]. Thus, according to the previous research, the following hypothesis is proposed:

Hypothesis 1 - The leader's ethical leadership has a significant effect on the subjective wellbeing of nurses.

Job satisfaction is a multidimensional notion related to a range of psychological and social elements [24]. Moreover, previous studies found a significant association between ethical leadership style and different organizational successes like job satisfaction $[24,26]$. Tu et al., [14] confirmed the effect of supervisors' ethical leadership on employee job satisfaction [13]. According to Robbins and Coulter [27], job satisfaction is an employee's general attitude to his/her job [28]. According to Qing et al., (2018), ethical leadership can predict job satisfaction positively in public sector organizations [10]. Moreover, Freire and Bettencourt [13] showed that ethical leadership had a positive effect on nurses' job satisfaction. Ruiz-Palomino et al. [29] stated that the significant connection between ethical leadership and job satisfaction was because of the central role of leaders in forming organizational culture and setting [30]. Kim and Brymer [8] also stated leaders' ethical conducts have positive relationships with an employee's enhanced job satisfaction with the current working condition and amount of payment [8]. Thus, based on the previous research, the following hypothesis is proposed:

Hypothesis 2 - The Leader's ethical leadership has a significant effect on the job satisfaction of nurses.

The mediation effect of job satisfaction on the relationship between ethical leadership and subjective wellbeing has not been sufficiently addressed in literature. Among rare existent studies, Ahanchian et al., [31] shows the positive effect of ethical leadership on life well-being of nurses mediated by job Satisfaction. However, they did not consider the subjective wellbeing of employees [27]. Mehari [32] also shows that job satisfaction indirectly mediates the effect of transformational leadership and employee well-being [29]. Indeed, it is the leader's ethical behavior that either directly or indirectly influences followers' subjective well-being. Hence, in line with these previous research findings, the following hypothesis is suggested:

Hypothesis 3 -Job satisfaction has a significant effect on the subjective wellbeing of nurses.

Hypothesis 4 - Job satisfaction significantly mediates the effect of ethical leadership on the subjective wellbeing of nurses.

Given the above three main hypotheses, the research conceptual model is presented as follows (Fig. 1): 


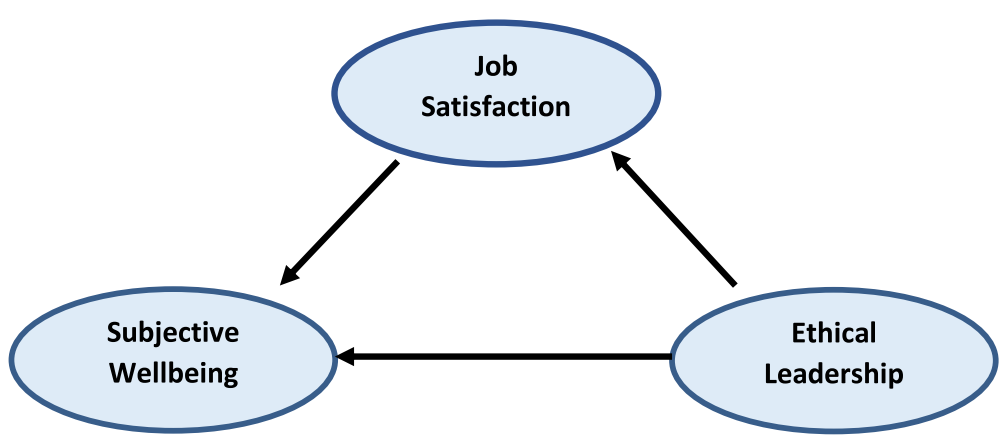

Fig. 1 Research Conceptual model (Source: Yang, 2014)

\section{Methods}

The present applied research was conducted as a descriptive-correlational survey in which the data were analyzed through covariance matrix using structural equation modeling (SEM) technique. The nurses of private hospitals in Mashhad (i.e. Bent-ol-Hoda, Mehr, Sina and Razavi hospitals) who were a sum of 730 in number comprised the statistical population of the present study.

As the statistical population was from several hospitals, the stratified sampling method has been used. First, four hospitals of Bent-ol-Hoda, Mehr, Sina and Razavi hospitals were randomly selected from the list of Mashhad private hospitals. By considering the error level for $5 \%$ in Cochran formula, the sample size was accurately estimated at 95\% confidence interval and significance level of 5\%, giving a sample size of 157 persons. Then, random sampling was performed from each hospital according to the ratio of sample to community (equivalent to 0.23 ). However, anticipating that a certain number of the questionnaires may not return, 200 questionnaires were actually distributed among nurses. Of these questionnaires, 166 completed questionnaires were eventually used in the analysis phase. The size of the population and the sample by stratums are given in Table 1.

Due to the limited number of populations, Cochran formula for finite population was used to determine the sample size. Using this sampling method, 157 participants were chosen (t 95\% confidence interval and significance level of 5\%) after pretesting a preliminary sample of 30 questionnaires, and substituting the Cochran formula's $5 \%$ error level. However, from the total number

Table 1 Population and sample size

\begin{tabular}{lll}
\hline Hospital & No. Nurses & Sample size \\
\hline Bent-ol-Hoda Hospital & 221 & $166 / 221^{*} 221=50.25$ \\
Mehr Hospital & 148 & 34 \\
Sina Hospital & 107 & 24 \\
Razavi hospitals & 254 & 58 \\
Sum & 730 & 166 \\
\hline
\end{tabular}

of 200 distributed questionnaires, only 166 ones were returned and used in the study's analysis step.

To assess the variables, 17 standard measures of Yang $[33,31]$ were used. Translation - back - translation method was used to make the measures ready to apply in the Iranian context. Five experts in the field of management and five working nurses in Mashhad's private hospitals verified the face and content validity of the final version of the questionnaire including 4 Job satisfaction' items, 9 ethical leadership's items, and 4 subjective wellbeing' items. All the items were rated on a five-point Likert scale ranging from strongly disagree (1) to strongly agree (5). In addition, the questionnaire's construct validity and reliability (internal consistency) were checked and confirmed using a confirmatory factor analysis and Cronbach's alpha, respectively. The result of calculated alpha showed an acceptable value of .81 which approves its sufficient reliability. Table 1 illustrated the calculated Cronbach's alphas for each variable, and Table 2 presents the results of the Pearson correlation test. For data analysis, Pearson correlation coefficient and SEM were used to estimate zero order correlation coefficients and to test the goodness of fit in structural equations using SPSS24 and Smart PLS3.

\section{Results}

\section{Descriptive statistics}

Respondents' demographic information was analyzed in terms of 4 variables: gender, age, education and years of service (work experience). According to the descriptive analysis, $68.1 \%$ of respondents were women and 31.9 were men; $32.5 \%$ aged between 20 and $30,38.6 \%$ between 31 and $40,22.9 \%$ between 41 and 50, 4.8\%

Table 2 Mean test

\begin{tabular}{lllll}
\hline Variable & Mean & St. Dev. & Sig & Status \\
\hline (1) Ethical leadership & 3.97 & .52 & 0.000 & Appropriate \\
(2) Job satisfaction & 3.33 & .69 & 0.000 & Appropriate \\
(3) SWB & 3.25 & .68 & 0.000 & Appropriate \\
\hline
\end{tabular}


Table 3 The results of Pearson correlation test

\begin{tabular}{llll}
\hline Variable & $\mathbf{( 1 )}$ & $\mathbf{( 2 )}$ & $\mathbf{( 3 )}$ \\
\hline (1) Ethical leadership & - & $.184^{*}$ & .103 \\
(2) Job satisfaction & $.184^{*}$ & - & $.560^{* *}$ \\
(3) SWB & .103 & $.560^{* *}$ & - \\
\hline $\begin{array}{l}\text { ** correlation at significance level of } p<0.01 ;{ }^{*} \text { correlation at significance level } \\
\text { of } p<0.05\end{array}$
\end{tabular}

between 51 and 60 , and $1.2 \%$ above $61 ; 15.7 \%$ were high school graduates, 18.7 junior college graduates, $42.8 \%$ university undergraduates, $12.7 \%$ university graduates, and $10.2 \%$ Ph.D. graduates; $28.9 \%$ had less than 5 years of working experience, $21.7 \%$ between 5 and 10 years, $21.1 \%$ between 10 and 15 years, $12 \%$ between 15 and 20 years, $12.7 \%$ between 20 and 25 years, and 3.6\% worked more than 25 years.

Table 2 presents Cronbach's alpha, mean response and the respective standard deviation of each variable. Note that the Cronbach's alpha for job satisfaction was initially .42, but after the exclusion of one item it rose to .82 .

As it can be observed in the above table, the mean responses for all variables are in an appropriate mean, among which the highest amount belongs to ethical leadership.

As the presence of a pairwise linear correlation between variables is a necessary assumption in applying the latent variables method in structural equation modeling (SEM), first, for each pair of variables, Pearson correlation test was run and the result is presented in Table 3.
As Table 2 shows, the strongest correlation is that of job satisfaction and SWB $(r=0.560)$, and the smallest correlation exists between SWB and ethical leadership $(r=0.103)$. In addition, all the estimated paired correlation coefficients are positive and significant.

\section{Validity and reliability of measurement and structural model}

The research model was analyzed by Smart PLS 3 employing structural equation modeling (SEM). The validity and reliability of the constructs was estimated using factor loadings, Cronbach's Alpha, composite Reliability average variance extracted (AVE) shown in Table 4.

As shown in Table 4, all factor loadings were more than 0.5 , shown appropriate reliability. Cronbach's $\alpha$ incidents were above 0.7 value showing satisfactory reliability. Moreover, the value of composite reliability and AVE were more than 0.7 and 0.5 respectively, showing satisfactory reliability [32].

To test the hypotheses, the partial least squares structural equation modeling (PLS-SEM) by Smart PLS 3 was employed. To test the fitness of structural model, R2 and Q2 measures were shown in Table 5.

As shown in Table 5, The first criterion for examining the structural model is the coefficient of determination R2 related to the endogenous (dependent) latent variables in the model and shows the effect of an exogenous variable on an endogenous variable. The strength of this effect interpreted with three values of $0.19,0.33$ and 0.67 as weak, medium and strong values [32]. Accordingly, the result shows that the model can predict $0.213 \%$ of

Table 4 Validity and reliability test

\begin{tabular}{|c|c|c|c|c|c|}
\hline Construct & Items & Factor loadings & Cronbach's alpha & Composite reliability & Average variance extracted (AVE) \\
\hline \multirow[t]{9}{*}{ Ethical Leadership } & 1 & 0.718 & \multirow[t]{9}{*}{$0 / 884$} & \multirow[t]{9}{*}{ 0/907 } & \multirow[t]{9}{*}{$0 / 523$} \\
\hline & 2 & 0.624 & & & \\
\hline & 3 & 0.807 & & & \\
\hline & 4 & 0.799 & & & \\
\hline & 5 & 0.816 & & & \\
\hline & 6 & 0.722 & & & \\
\hline & 7 & 0.670 & & & \\
\hline & 8 & 0.589 & & & \\
\hline & 9 & 0.718 & & & \\
\hline \multirow[t]{3}{*}{ Job Satisfaction } & 10 & 0.848 & \multirow[t]{3}{*}{$0 / 768$} & \multirow[t]{3}{*}{ 0/865 } & \multirow[t]{3}{*}{$0 / 683$} \\
\hline & 11 & 0.891 & & & \\
\hline & 12 & 0.733 & & & \\
\hline \multirow{5}{*}{$\begin{array}{l}\text { Subjective } \\
\text { Wellbeing }\end{array}$} & 13 & 0.734 & \multirow[t]{5}{*}{ 0/790 } & \multirow[t]{5}{*}{$0 / 856$} & \multirow[t]{5}{*}{$0 / 543$} \\
\hline & 14 & 0.731 & & & \\
\hline & 15 & 0.763 & & & \\
\hline & 16 & 0.764 & & & \\
\hline & 17 & 0.689 & & & \\
\hline
\end{tabular}


Table $\mathbf{5}$ Goodness of fit of structural model

\begin{tabular}{lllll}
\hline & SSO & SSE & Q $^{2}$ (=1-SSE/SSO) & R Square \\
\hline Ethical Leadership & $1494 / 000$ & $1494 / 000$ & & $0 / 131$ \\
Job Satisfaction & $498 / 000$ & $432 / 517$ & $0 / 213$ \\
Subjective Wellbeing & $830 / 000$ & $626 / 835$ & $0 / 245$ & $0 / 495$ \\
\hline
\end{tabular}

job satisfaction changes, measured as a mediate effect. Moreover, $49 \%$ of subjective wellbeing changes predicted by the model, showed strong effects of exogenous variables of the model on subjective well-being. Q2 value determines the strength of the model in predicting dependent variables. Hair et al., [34] considered three values of $0.02,0.15$ and 0.35 as low, medium and strong predictive strength [32]. As shown in Table 4, the value of Q2 for all dependent variables were moderate.

\section{Test of hypotheses}

To test the hypotheses, PLS-SEM by Smart PLS 3 was employed. Figure 2 shows the SME model in $T$-value mood:

According to Fig. 2, the relationship between variables are significant when the $T$-value was more than 1.96. As shown in Fig. 2, all hypotheses of the research were accepted. The result of hypothesis tests is shown in Table 6.

According to Table 4, all hypothesis was supported. Thus, the impact of ethical leadership $(\beta=0.155, T$ value $=2.420)$ and job satisfaction $(\beta=0.619 T$-value $=$ $11.338)$ on subjective wellbeing are significant. Moreover, the effect of ethical leadership on job satisfaction is supported $(\beta=0.462 T$-value $=7.445)$.

\section{Testing mediation effects}

To measure mediation effect of job satisfaction in the relationship between ethical leadership and subjective wellbeing, the indirect effect shown in Table 7.

As shown in Table 4, the indirect effect of ethical leadership on subjective wellbeing through job satisfaction is confirmed $(\beta=0.286, T$-value $=7.160)$, shown the mediation effect of job satisfaction. The result also shows that the indirect effect of ethical leadership on subjective wellbeing through job satisfaction is more than the direct effect of ethical leadership on subjective wellbeing $(\beta=0.155, T$-value $=2.420)$. Accordingly, the total effect (direct effect" indirect effect) of ethical leadership on subjective wellbeing is 0.443 .

\section{Discussion}

The aim of this study was to investigate the relationship between moral leadership and subjective wellbeing with the mediating role of job satisfaction among nurses in four private hospitals in Mashhad. This study is based on social identity theory which states that nurses' behavior is influenced by the behavior of their managers and leaders, leading nurses to be identified in the workplace. The results of data analysis showed that there is a significant relationship between research variables. In general, this study had two main conclusions: The first one

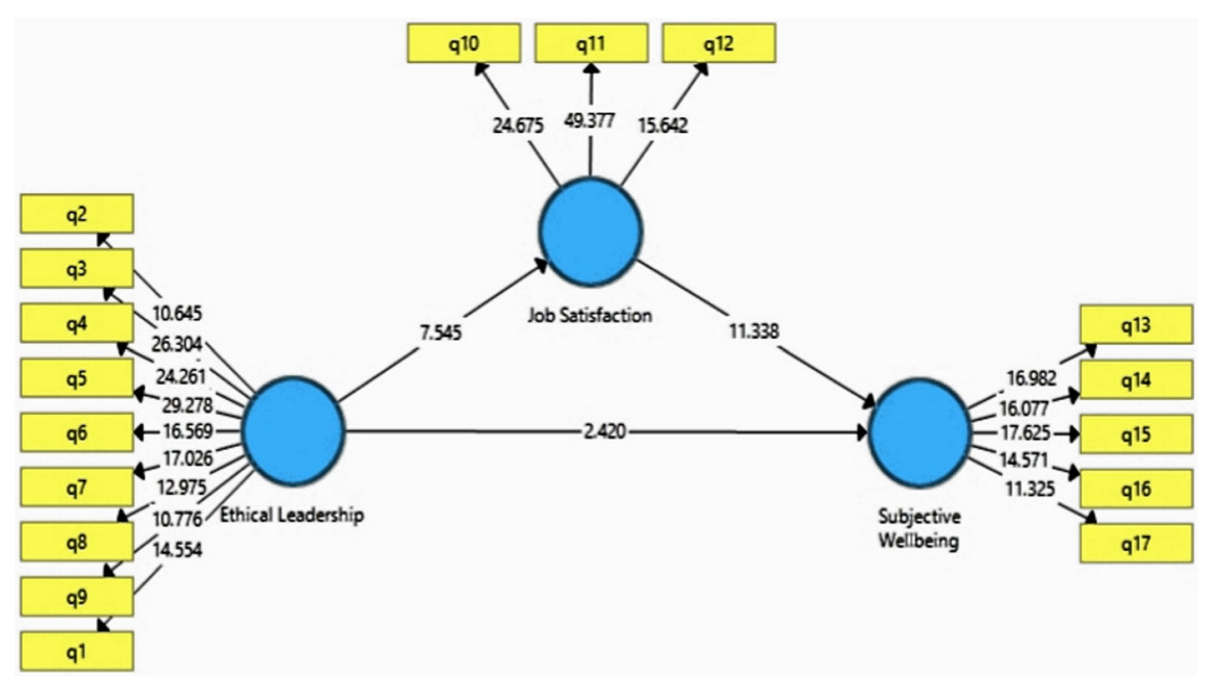

Fig. 2 SME model in T-value mood 
Table 6 Summary of hypotheses testing results

\begin{tabular}{llll}
\hline & Standard path coefficients & T-value & Results \\
\hline Ethical Leadership - > Job Satisfaction & 0.462 & 7.445 & Supported \\
Job Satisfaction - > Subjective Wellbeing & 0.619 & 11.338 & Supported \\
Ethical Leadership - > Subjective wellbeing & 0.155 & 2.420 & Supported \\
\hline
\end{tabular}

reveals that ethical leadership directly and indirectly affects nurses' happiness. Therefore, we can conclude that moral leadership affects not only the work of an individual but also the subjective wellbeing of nurses, which is in line with Yang [31], Teimouri et al., [25] and Sarwar et al., [22]. Zou et al., [22] also show the effect of spiritual leadership on the nurse's subjective well-being [23]. In this regard, the authors also conducted interviews with the nurses under study, which they also confirmed and stated that the ethical leadership style in the hospital can greatly affect their mental happiness and feeling of happiness. The second conclusion indicates that ethical leadership affects nurses' job satisfaction, which is in line with the study of Ngabonzima et al., [35], Ganji et al., [36] and Tu et al., [15]. Moreover, the results also are in line with Freire and Bettencourt [12] study, shown the positive effect of ethical leadership on nurses' job satisfaction. In this regard, a number of additional interviews were conducted with some nurses who also emphasized that ethical leadership style has an impact on their job satisfaction. The results also confirmed the mediation effect of job satisfaction on subjective wellbeing, which is in consistent with Ahanchian et al. [27] and Mehari [29] studies.

These results, seen in a broader context, point to the increasing importance of ethically-oriented leadership in the target organization and healthcare institutions. Appreciating admirable human values, and being supportive and inspiring to nurses and other employees in the healthcare sector would create a feeling of usefulness and efficacy, pave the way for effective task performance and satisfy psychological needs. The ethically oriented approach in leadership has many benefits for organizations, which are more obvious and noticeable in the health management system and the nursing staff due to the dominance of an intimate and strongly emotional atmosphere. The particular working state and atmosphere of hospitals require such closeness and company among nurses, staff members, physicians, and patients. Naturally, through this closeness, many ethical issues are highlighted. The prevalence of ethical leadership in hospitals makes managers of sections and units further committed to ethical principles and somehow set an example for subordinates. We may then expect practice of ethical behaviors from nurses and staff members. Leadership, by definition, means influence and persuasion of others as distinguished from management by its emphasis on voluntary compliance of subordinates. Indeed, leadership behavior, in itself, is effective, supportive, stimulating and significant and when seasoned by the consideration of ethics and as an ethical model, it takes a more pleasing color which significantly contributes to the establishment of ethical rules in the organization. Our results, in general, support the promotion of ethical leadership in private hospitals through formal planning and top management initiatives both for the good of employee's working conditions and the quality of the services provided.

\section{Conclusion}

In the present study, the correlation between ethical leadership and job satisfaction, and also its (their) relation with subjective wellbeing with and without the nursing staff's job satisfaction as the mediator was examined in Mashhad. The results indicated that ethical leadership has a significant influence on job satisfaction and subjective wellbeing. Accordingly, results show that job satisfaction, among nurses, was facilitated by the influence of ethical leadership on subjective wellbeing. Accordingly, because the principled leader of the hospital increases the feeling of satisfaction in nurses by adhering to ethical principles, fair and equitable resolution of issues, listening to the conversations and concerns of nurses, and sympathy and solving their problems, then nurse job satisfaction and subjective well-being would be increased. Ethical leadership and the basic standards of the business as well as establishing, validating and collaborating these values and standards must be integrated into the central standards and ideas of the firm by the hospital's directors and managers. Moreover, administrators and chief managements should actively be engaged in practicing the ethical leadership and should also show a good ethical management skill.

Table 7 Summary of hypotheses testing results

\begin{tabular}{llllll}
\hline & Indirect effect & & Total effect \\
\cline { 2 - 3 } & Standard path coefficients & $T$ Value & Standard path coefficients & $\boldsymbol{T}$ Value \\
\hline Ethical Leadership - > Job Satisfaction - > Subjective Wellbeing & 0.286 & 7.160 & 0.443 & 6.705 \\
\hline
\end{tabular}




\section{Acknowledgements}

This research was supported/partially supported by [Private Hospitals Nurses Private Hospitals Office Section]. I thank from Ferdowsi University of Mashhad [vice president for research \& technology] who provided insight and expertise that greatly assisted the research.

\section{Declarations}

Not applicable

\section{Authors' contributions}

SS carried out data gathering, statistical analyses of the data and interview with nurses. AK designed the study and performed the histological examination of the Ethical Leadership, and was a major contributor in writing the manuscript. All authors read and approved the final manuscript.

\section{Funding}

Not applicable

\section{Availability of data and materials}

The datasets used and/or analyzed during the current study are available from the corresponding author on reasonable request. For having this data please contact AK. kafashpor@um.ac.ir

\section{Ethics approval and consent to participate}

This work is supported by grant NO.52087 from Vice president for Research \&Technology and written informed consent was obtained from the participants. The ethical protocols were approved by the Ethics Committee of Ferdowsi University of Mashhad. We reviewed all 166 completed questionnaires admitted to Ferdowsi university of Mashhad between 13/3/ 2018 and 20/8/2018 after approval of ethical committee of Human Research (NO. 52087), the study was carried out based on data collection from Mashhad private hospitals.

\section{Consent for publication}

Not Applicable

\section{Competing interests}

The authors declare that they have no competing interests.

\section{Author details}

${ }^{1}$ Management Department, Faculty of Economics and Administrative Sciences, Ferdowsi University of Mashhad, Mashhad, Iran. ${ }^{2}$ Department of Management, Tabaran Institute of Higher Education, Mashhad, Iran.

Received: 3 March 2020 Accepted: 28 October 2020

Published online: 30 November 2020

\section{References}

1. Mahsud R, Yukl G, Prussia G. Leader empathy, ethical leadership, and relations-oriented behaviors as antecedents of leader-member exchange quality. J Manag Psychol. 2010; https://doi.org/10.1108/02683941011056932.

2. Ghasemour Ganji SF, Rahim Nia F, Ahanchian MR, Syed J. Analyzing the impact of diversity management on innovative behaviors through employee engagement and affective commitment. Iran J Manag Stud. 2020; https://doi.org/10.22059/JJMS.2020.307781.674164.

3. Dion M. Are ethical theories relevant for ethical leadership? Leadersh Org Dev J. 2012; https://doi.org/10.1108/01437731211193098.

4. Walumbwa FO, Hartnell CA, Misati E. Does ethical leadership enhance group learning behavior? Examining the mediating influence of group ethical conduct, justice climate, and peer justice. J Bus Res. 2017;72:14-23 https://doi.org/10.1016/j.jbusres.2016.11.013.

5. Wang Z, Xing L, Xu H, Hannah ST. Not all followers socially learn from ethical leaders: the roles of followers' moral identity and leader identification in the ethical leadership process. J Bus Ethics. 2019:1-21 https://doi.org/10.1007/s10551-019-04353-y.

6. Brown ME, Treviño LK, Harrison DA. Ethical leadership: a social learning perspective for construct development and testing. Organ Behav Hum Decis Process. 2005:97(2):117-34 https://doi.org/10.1016/.obhdp.2005.03.002

7. de Bettignies HC, Ip K, Xuezhu B, Habisch A, Lenssen G, Ip PK. Practical wisdom of Confucian ethical leadership: a critical inquiry. J Manag Dev. 2011; https://doi.org/10.1108/02621711111150209.
8. Kim WG, Brymer RA. The effects of ethical leadership on manager job satisfaction, commitment, behavioral outcomes, and firm performance. Int J Hosp Manag. 2011;30(4):1020-6 https://doi.org/10.1016/j.ijhm.2011. 03.008.

9. Zhang FW, Liao JQ, Yuan JM. Ethical leadership and whistleblowing: collective moral potency and personal identification as mediators. Soc Behav Personal Int J. 2016;44(7):1223-31.

10. Kalshoven K, Den Hartog DN. Ethical leader behavior and leader effectiveness: the role of prototypicality and trust. Int I Leadersh Stud. 2009; 5(2):102-20 https://hdl.handle.net/11245/1.317773.

11. Qing M, Asif M, Hussain A, Jameel A. Exploring the impact of ethical leadership on job satisfaction and organizational commitment in public sector organizations: the mediating role of psychological empowerment. Rev Manag Sci. 2019:1-28 https://doi.org/10.1007/s1 1846-019-00340-9.

12. Ren $\mathrm{S}$, Chadee D. Ethical leadership, self-efficacy and job satisfaction in China: the moderating role of guanxi. Pers Rev. 2017;46(2):371-88 https:// doi.org/10.1108/PR-08-2015-0226.

13. Freire $C$, Bettencourt $C$. Impact of ethical leadership on job satisfaction: the mediating effect of work-family conflict. Leadersh Org Dev J. 2020;41(2): 319-30 https://doi.org/10.1108/LODJ-07-2019-0338.

14. Tu Y, Lu X, Yu Y. Supervisors' ethical leadership and employee job satisfaction: a social cognitive perspective. J Happiness Stud. 2017;18(1):22945 https://doi.org/10.1007/s10902-016-9725-1.

15. Ahmad S, Sohal AS, Cox JW. Leading well is not enough: a new insight from the ethical leadership, workplace bullying and employee well-being relationships. Eur Bus Rev. 2020;32(2):159-80 https://doi.org/10.1108/EBR-08-2018-0149.

16. Rivers J, Thompson N, Jeske D. Dedicated but exhausted? The role of ethical leadership for employee wellbeing in UK student unions. J Hum Resour Manage. 2018;21 (2):16-27.

17. Kuoppala J, Lamminpää A, Liira J, Vainio H. Leadership, job well-being, and health effects - a systematic review and a meta-analysis. J Occup Environ Med. 2008:50(8):904-15.

18. Vincent-Höper S, Teetzen F, Gregersen S, Nienhaus A. Leadership and employee well-being. In: Research handbook on work and well-being: Edward Elgar Publishing; 2017. https:/www.elgaronline.com/view/edcoll/ 9781785363252/9781785363252.00021 xml.

19. Gilbert SL, Kelloway EK. Leadership, recognition and well-being: a moderated mediational model. Can J Adm Sci. 2018:35(4):523-34 https:// doi.org/10.1002/cjas.1477.

20. Arnold KA. Transformational leadership and employee psychological wellbeing: a review and directions for future research. J Occup Health Psychol. 2017;22(3):381 https://doi.org/10.1037/ocp0000062.

21. Hendriks M, Burger M, Rijsenbilt A, Pleeging E, Commandeur H. Virtuous leadership: a source of employee well-being and trust. Manag Res Rev. 2020;43(8):951-70 https://doi.org/10.1108/MRR-07-2019-0326.

22. Zou W, Zeng $Y$, Peng $Q, X i n ~ Y$, Chen J, Houghton J. The influence of spiritual leadership on the subjective well-being of Chinese registered nurses. J Nurs Manag. 2020;28(6):1432-42 https:/doi.org/10.1111/jonm.13106.

23. Kalshoven K, Boon CT. Ethical leadership, employee well-being, and helping. J Pers Psychol. 2012. https://doi.org/10.1027/1866-5888/a000056.

24. Teimouri $\mathrm{H}$, Hosseini $\mathrm{SH}$, Ardeshiri A. The role of ethical leadership in employee psychological well-being (case study: Golsar Fars company). J Hum Behav Soc Environ. 2018;28(3):355-69 https://doi.org/10.1080/ 10911359.2018.1424063.

25. Chughtai A, Byrne M, Flood B. Linking ethical leadership to employee wellbeing: the role of trust in supervisor. J Bus Ethics. 2015;128(3):653-63 https://doi.org/10.1007/s10551-014-2126-7.

26. Sarwar $H$, Ishaq MI, Amin A, Ahmed R. Ethical leadership, work engagement, employees' well-being, and performance: a cross-cultural comparison. J Sustain Tour. 2020:1-19 https://doi.org/10.1080/09669582.2020.1788039.

27. Robbins SP, Coulter M. Principles of management. Translated by Seyyed Mohammad Arabi and Mohammed Ali Hamid Rafiee and Behrouz Asrar Ershad. 4th ed. Tehran: Office of Cultural Studies; 2007. http://wagnerhigh. net/ourpages/auto/2011/10/5/64504902/LE400_CH00_FM_pi-xiii_cd.pdf.

28. Ganji SF, Johnson LW. The relationship between family emotional support, psychological capital, female job satisfaction and turnover intention. Int J Econ Bus Manag Stud. 2020;7(1):59-70. https://doi.org/ $10.20448 / 802.71 .59 .70$

29. Ruiz-Palomino P, Ruiz-Amaya C, Knörr H. Employee organizational citizenship behaviour: the direct and indirect impact of ethical leadership. Can J Adm Sci. 2011;28(3):244-58 https://doi.org/10.1002/cjas.221. 
30. Lam T, Zhang H, Baum T. An investigation of employees' job satisfaction: the case of hotels in Hong Kong. Tour Manag. 2001;22(2):157-65 https://doi. org/10.1016/S0261-5177(00)00039-X.

31. Ahanchian MR, Yazdani P, Sadeghian S. The effect of ethical leadership on life satisfaction and well-being by mediation of job satisfaction: the case of private hospitals in Mashhad city. Public Manag Res. 2018;10(38):171-96.

32. Mehari, B. Transformational leadership and well-being: The mediating role of trust in leadership, meaningfulness and job satisfaction. 2015. https://doi. org/10.13140/RG.2.1.1362.4489.

33. Yang C. Does ethical leadership lead to happy workers? A study on the impact of ethical leadership, subjective well-being, and life happiness in the Chinese culture. J Bus Ethics. 2014;123(3):513-25 https://doi.org/10.1007/ s10551-013-1852-6.

34. Hair JF, Ringle CM, Sarstedt M. PLS-SEM: indeed, a silver bullet. J Mark Theory Pract. 2014;19(2):137-49 https://doi.org/10.2753/MTP10696679190202.

35. Ngabonzima A, Asingizwe D, Kouveliotis K. Influence of nurse and midwife managerial leadership styles on job satisfaction, intention to stay, and services provision in selected hospitals of Rwanda. BMC Nurs. 2020;19:1-11 https://doi.org/10.1186/s12912-020-00428-8.

36. Ganji EFG, Kafashpour A, Sorkhan VB. The effect of ethical context perceptions to the job response: emphasizing work value (case of study: female staff at Ferdowsi University of Mashhad). Q J Women Stud Socio Psychol. 2017;14(4):69-94.

\section{Publisher's Note}

Springer Nature remains neutral with regard to jurisdictional claims in published maps and institutional affiliations.

Ready to submit your research? Choose BMC and benefit from:

- fast, convenient online submission

- thorough peer review by experienced researchers in your field

- rapid publication on acceptance

- support for research data, including large and complex data types

- gold Open Access which fosters wider collaboration and increased citations

- maximum visibility for your research: over $100 \mathrm{M}$ website views per year

At $\mathrm{BMC}$, research is always in progress.

Learn more biomedcentral.com/submissions 